\title{
Fine-scale 3-dimensional movement behaviour of silky sharks Carcharhinus falciformis associated with fish aggregating devices (FADs)
}

\author{
John Filmalter ${ }^{1,2,3, *}$, Paul Cowley ${ }^{2,1}$, Fabien Forget ${ }^{1,2,3}$, Laurent Dagorn ${ }^{3}$ \\ ${ }^{1}$ Department of Ichthyology and Fisheries Science, Rhodes University, Grahamstown 6140, South Africa \\ ${ }^{2}$ South African Institute for Aquatic Biodiversity, Grahamstown 6140, South Africa \\ ${ }^{3}$ Institut de Recherche pour le Développement, UMR MARBEC (IRD, Ifremer, Univ. Montpellier, CNRS), \\ Avenue Jean Monnet CS 30171, 34203 Sète cedex, France
}

\begin{abstract}
The silky shark Carcharhinus falciformis is the primary elasmobranch bycatch in the global tuna purse seine fishery using fish aggregating devices (FADs). Information on the associative behaviour of this species with floating objects remains limited. Here the use of various electronic tags provided important new insight into this behaviour. Thirty-eight juvenile silky sharks (69 to $116 \mathrm{~cm}$ total length; TL) were tagged with acoustic tags at 9 drifting FADs equipped with satellite-linked acoustic receivers in the western Indian Ocean (total monitoring $=154 \mathrm{~d}$ ). Presence/absence and swimming depth data were transmitted from the receivers. A subset of 17 individuals was also fitted with pop-up satellite archival tags (PSATs; $n=13$ ), or internal archival tags $(\mathrm{n}=4)$. Behavioural data were successfully collected from 20 of the tagged sharks, covering a total of $300 \mathrm{~d}$. Fine-scale movements of one individual were observed by active tracking, lasting $2 \mathrm{~h}$ 46 min. Sharks remained associated with the FAD where they were tagged for extended periods ( 2.84 to $30.60 \mathrm{~d}$, mean $=15.69 \mathrm{~d}$ ). Strong diel changes were observed in both FAD association and swimming depth. Typically, individuals moved away from FADs after sunset and returned later that night, then remained closely associated until the following evening. Vertical behaviour also changed around sunset, with sharks using fairly constant depths, $>25 \mathrm{~m}$, during the day and switching to rapid vertical movements during the night, with descents $>250 \mathrm{~m}$ recorded. The actively tracked individual returned to a FAD from $>1.2 \mathrm{~km}$ away. Long residence times and close association highlight the vulnerability of silky sharks to incidental capture in FAD fisheries.
\end{abstract}

KEY WORDS: Shark $\cdot$ Behaviour $\cdot$ Telemetry $\cdot$ FAD $\cdot$ Bycatch

\section{INTRODUCTION}

Tuna purse seine vessels targeting tropical tuna species deploy large numbers of drifting fish aggregating devices (FADs) throughout the world's tropical and subtropical waters. Over time these FADs aggregate huge numbers of tunas as well as several non-tuna pelagic species. The principal species targeted through this practice are skipjack tuna Katsuwonus pelamis, yellowfin tuna Thunnus albacares and bigeye tuna T. obesus. Deployed FADs are left

\footnotetext{
${ }^{*}$ Corresponding author: jdfilmalter@gmail.com
}

to drift for several weeks or months before being revisited to capture the aggregated fish biomass. Vessel skippers monitor the positions of their deployed FADs using a GPS buoy attached to the FAD (Lopez et al. 2014). While the vast majority (typically 95\%) of the aggregated biomass consists of the targeted tuna species (Gilman 2011, Dagorn et al. 2013), several other species also aggregate around FADs and are thus taken as bycatch. These species include a variety of pelagic teleosts such as dorado Coryphaena hippurus, rainbow runner Elagatis bipinnulata,

() The authors 2015. Open Access under Creative Commons by Attribution Licence. Use, distribution and reproduction are unrestricted. Authors and original publication must be credited. 
oceanic triggerfish Canthidermis maculata and wahoo Acanthocybium solandri, as well as elasmobranchs, such as the silky shark Carcharhinus falciformis and the oceanic whitetip shark Carcharhinus longimanus.

The use of FADs as fishing tools has grown in popularity throughout the various fleets across all oceans in the past 2 decades. This practice now accounts for approximately $60 \%$ of the total tropical tuna (skipjack tuna, yellowfin tuna and bigeye tuna) purse seine catch and $40 \%$ of the global tropical tuna landings (Dagorn et al. 2013). The growing popularity of FADs amongst fishers has led to concerns regarding not only the over exploitation of tuna stocks, but also the impact this practice has on bycatch species, such as elasmobranchs with life history traits poorly suited to high exploitation rates. Silky sharks dominate elasmobranch catches at FADs and constitute approximately $90 \%$ of sharks caught in this fishery across all oceans (Gilman 2011), and, in the Indian Ocean specifically, represent at least $75 \%$ of the shark catch, by number (Amandè et al. 2010). As the use of FADs continues to increase in this fishery (Dagorn et al. 2013), there is a direct need to understand how these changing practices will influence silky shark populations. Understanding the details of the species' associative behaviour is a key step toward fulfilling this knowledge gap. This information can then be integrated into modelling approaches used to predict how changing FAD densities can affect populations, such as those recently described for tunas by Sempo et al. (2013).

To date, 2 studies, Dagorn et al. (2007b) and Filmalter et al. (2011), have provided information on the behaviour of silky sharks associated with FADs. While both provide some insights into the behaviour of this species, more detailed information is essential for obtaining a better understanding of this associative behaviour. As such, the broad aim of this study was to investigate the fine-scale behaviour of silky sharks associated with drifting FADs in the western Indian Ocean using electronic tagging methods. The specific objectives were to (1) characterise the residence times of silky sharks at drifting FADs; (2) assess temporal patterns in associative behaviour; (3) characterise vertical behaviour during periods of association; and (4) investigate detailed horizontal and vertical movements around a FAD and within the aggregated community.

\section{MATERIALS AND METHODS}

\section{Shark tagging}

Juvenile silky sharks were caught using baited handlines at 9 drifting FADs (Table 1) in the western Indian Ocean (Fig. 1) during 4 research cruises conducted between 2010 and 2012. Each shark was surgically equipped (hereafter 'tagged') with either V13 or V13P acoustic tags, (V13-1L-64K Vemco, a division of Amirix Systems) transmitting at $69 \mathrm{kHz}$. The transmitters had a $90 \mathrm{~s}$ nominal delay (range: 50 to $130 \mathrm{~s})$ and an expected minimum battery life of $879 \mathrm{~d}$. Tagging was carried out following standard fish tag implantation techniques (Schaefer \& Fuller 2005, Dagorn et al. 2007a). Briefly, sharks were landed using a scoop net, placed in dorsal recumbency in a padded cradle, their eyes covered with a wet cloth and a hose pumping sea water placed in the mouth to irrigate the gills. A small incision was then made, using a scalpel, along the ventral mid line, roughly $4 \mathrm{~cm}$ anterior to the cloaca. Once the peritoneal lining was penetrated, the tag, which had been cleansed in ethanol and air dried, was inserted and the incision closed with 2 independent braided sutures.

In addition to the internal acoustic tag, a subsample of sharks was also fitted with either an internal archival tag (MK 9, Wildlife Computers) $(\mathrm{n}=4)$ or a pop-up satellite archival tag (PSAT) (miniPAT, Wildlife Computers) $(\mathrm{n}=13)$. The internal archival tags were inserted through the same incision as the acoustic tag prior to suturing, such that the light stalk with external thermistor protruded from the anterior end of the incision. Alternatively, miniPATs were attached externally to the animal using 2 attachment techniques. Either the tag was tethered to a nylon anchor (36 mm Wilton dart, Wildlife Computers),

Table 1. Metadata of FADs where silky sharks Carcharhinus falciformis were captured and tagged in the western Indian Ocean. Dates given as dd/mm/yy

\begin{tabular}{|lcccccc|}
\hline $\begin{array}{l}\text { FAD } \\
\text { ID }\end{array}$ & $\begin{array}{c}\text { Monitoring } \\
\text { start date }\end{array}$ & $\begin{array}{c}\text { Monitoring } \\
\text { end date }\end{array}$ & $\begin{array}{c}\text { No. } \\
\text { monitoring } \\
\text { days }\end{array}$ & $\begin{array}{c}\text { No. } \\
\text { sharks } \\
\text { tagged }\end{array}$ & $\begin{array}{c}\text { No. } \\
\text { sharks } \\
\text { detected }\end{array}$ & $\begin{array}{c}\text { Drift } \\
\text { distance } \\
(\mathrm{km})\end{array}$ \\
\hline FAD 1 & $13 / 03 / 10$ & $24 / 03 / 10$ & 11 & 1 & 1 & 346 \\
FAD 2 & $15 / 03 / 10$ & $27 / 03 / 10$ & 12 & 4 & 4 & 365 \\
FAD 3 & $15 / 04 / 11$ & $08 / 05 / 11$ & 23 & 1 & 0 & 930 \\
FAD 4 & $20 / 04 / 11$ & $15 / 05 / 11$ & 25 & 3 & 1 & 1193 \\
FAD 5 & $18 / 06 / 11$ & $22 / 06 / 11$ & 4 & 7 & 3 & 87 \\
FAD 6 & $20 / 06 / 11$ & $20 / 06 / 11$ & 0 & 6 & 0 & 30 \\
FAD 7 & $22 / 06 / 11$ & $08 / 07 / 11$ & 16 & 1 & 1 & 268 \\
FAD 8 & $02 / 04 / 12$ & $04 / 05 / 12$ & 32 & 3 & 1 & 730 \\
FAD 9 & $13 / 04 / 12$ & $14 / 05 / 12$ & 31 & 13 & 10 & 854 \\
\hline
\end{tabular}




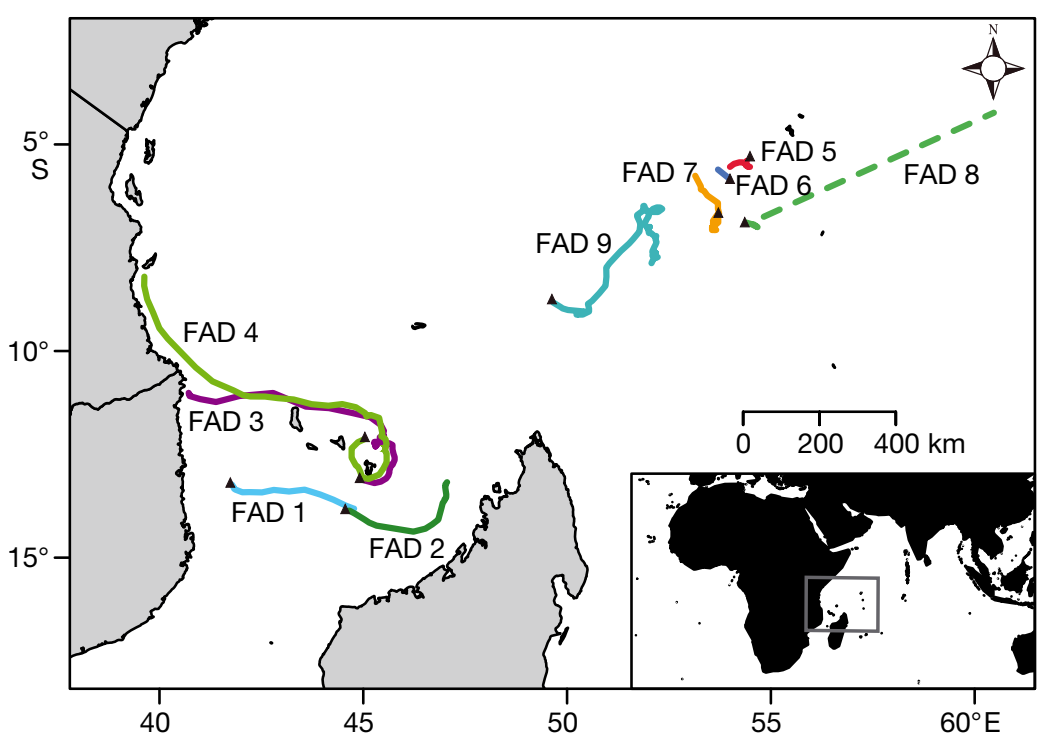

Fig. 1. Location and drift trajectories of the 9 drifting FADs monitored during this study. ( $\mathbf{\Lambda})$ Start points; dashed line: straight-line distance between deployment and retrieval of the VR2 receiver on FAD 8 where no positional estimates could be obtained

which was inserted into the dorsal musculature of the shark at the base of the first dorsal fin, or the tag was mounted on the first dorsal fin. Fin-mounted tags were attached to a nylon rod passed through the base the posterior region of the dorsal fin. The selection of the attachment method used was based on the size of the individual and the availability of materials. Generally, intramuscular darts were used on larger individuals. Before release, the total length (TL) of each shark was measured from the tip of the snout to the end of the dorsal lobe of the caudal fin, using a pair of callipers. The sex was then determined visually and the individual released directly adjacent to the FAD.

\section{Passive acoustic tracking}

Prior to the commencement of fishing for sharks, a FAD was equipped with a satellite-linked acoustic receiver (VR4-GLOBAL, Vemco). This receiver automatically detected and stored data from the acoustic tags and then transmitted it via the Iridium satellite system on a daily basis. The information obtained from these receivers included the tag identification code, time of reception of each acoustic transmission that was detected and the swimming depth of those individuals equipped with pressure-sensitive tags. Once tagging was completed, the FAD and receiver were abandoned to facilitate extended observation of the tagged individuals' behaviour. The receiver also provided positional information, allowing the drift of the FAD to be monitored remotely. In one instance, a conventional acoustic receiver (VR2W, Vemco) was attached to the FAD instead of the satellite-linked receiver. This receiver archived the information from the tagged animals and was later recovered and the data downloaded manually. No positional data were obtained for this FAD (FAD 8 in Table 1).

\section{Active tracking}

A previous study on the behaviour of silky sharks at FADs (Filmalter et al. 2011) found that individuals often left the vicinity of the FAD directly after tagging, returning several days later. To investigate this behavioural phenomenon further, one individual was caught and tagged with a V16P 3H continuous pinger (Table 2). This tag transmitted an acoustic signal once per second, allowing the animal to be actively tracked. Tracking was conducted only during daylight hours from a small $(5 \mathrm{~m})$ auxiliary boat belonging to a commercial purse seine vessel. A portable Vemco VR100 receiver, equipped with a uni-directional VH-110 hydrophone set to detect the continuous tag at a frequency of $51 \mathrm{kHz}$, was used. This receiver was also set to simultaneously detect other fishes and sharks that had been tagged with coded tags transmitting on $69 \mathrm{kHz}$ on a second reception channel. Owing to the use of the directional hydrophone, any detections recorded on this receiver during the active tracking were assumed to originate from animals behind the shark being tracked or, alternatively, between the shark and the tracking boat. After release, the shark was followed by the tracking boat. The gain on the receiver was set to 0 throughout the experiment, to minimise the distance between the boat and the shark, and the boat's position was assumed to represent the position of the shark. The positions of both the FAD and the boat were monitored throughout the experiment using 2 hand-held GPS units (Garmin E-Trex), one of which was placed in a waterproof container on the FAD, and the second on the tracking boat. These units were set to automatically record their location, accurate to $10 \mathrm{~m}$, every 8 to $10 \mathrm{~s}$. 
Table 2. Metadata for silky sharks Carcharhinus falciformis tagged with electronic tags at drifting FADs in the western Indian Ocean between 2010 and 2012. Dates given as dd/mm/yy. CRT: continuous residence time; TL: total length; F: female; M: male

\begin{tabular}{|c|c|c|c|c|c|c|c|c|c|c|}
\hline $\begin{array}{l}\text { Tagging } \\
\text { date }\end{array}$ & $\begin{array}{l}\text { Tagging } \\
\text { time }\end{array}$ & $\begin{array}{l}\text { FAD } \\
\text { ID }\end{array}$ & $\begin{array}{c}\text { Size } \\
\text { (cm TL) }\end{array}$ & Sex & $\begin{array}{l}\text { Tag } \\
\text { type }\end{array}$ & $\begin{array}{l}\text { Acoustic } \\
\text { tag ID }\end{array}$ & $\begin{array}{l}\text { No. total } \\
\text { detections }\end{array}$ & $\begin{array}{c}\text { Total association } \\
\text { time (d) }\end{array}$ & $\begin{array}{l}\text { CRT } \\
\text { (d) }\end{array}$ & $\begin{array}{c}\text { PSAT/archival } \\
\text { tag ID }\end{array}$ \\
\hline $13 / 03 / 10$ & $16: 50$ & FAD 1 & 88 & $\mathrm{~F}$ & V13P & 64759 & 6210 & 10.44 & 8.72 & 34419 \\
\hline $15 / 03 / 10$ & $17: 17$ & FAD 2 & 109 & M & V13P & 64760 & 4273 & 11.56 & 11.03 & 34420 \\
\hline $15 / 03 / 10$ & $18: 17$ & FAD 2 & 77 & $\mathrm{~F}$ & V13P & 64762 & 1740 & 6.36 & 6.36 & - \\
\hline $16 / 03 / 10$ & 09:35 & FAD 2 & 77 & $\mathrm{~F}$ & V13P & 64798 & 2460 & 10.88 & 10.88 & - \\
\hline $16 / 03 / 10$ & $10: 47$ & FAD 2 & 81 & $\mathrm{~F}$ & V13P & 64799 & 1099 & 6.31 & 6.31 & - \\
\hline $15 / 04 / 11$ & $15: 40$ & FAD 3 & 91 & M & V13P & 64772 & 0 & 0 & 0 & 34206 \\
\hline $20 / 04 / 11$ & $16: 54$ & FAD 4 & 103 & $\mathrm{~F}$ & V13P & 64777 & 0 & 0 & 0 & 98719 \\
\hline $20 / 04 / 11$ & $17: 00$ & FAD 4 & 98.5 & M & V13P & 64778 & 0 & 0 & 0 & 34366 \\
\hline 20/04/11 & $22: 57$ & FAD 4 & 80 & $\mathrm{~F}$ & V13P & 64779 & 5422 & $16.81^{\mathrm{a}}$ & 14.79 & - \\
\hline 18/06/11 & $11: 07$ & FAD 5 & 98 & $\mathrm{~F}$ & V13P & 64781 & 0 & 0 & 0 & 94261 \\
\hline $18 / 06 / 11$ & $10: 49$ & FAD 5 & 75.5 & $\mathrm{~F}$ & V13TP & 64158 & 0 & 0 & 0 & - \\
\hline 18/06/11 & $11: 30$ & FAD 5 & 73.5 & $\mathrm{~F}$ & V13 & 54269 & 0 & 0 & 0 & - \\
\hline 18/06/11 & $11: 50$ & FAD 5 & 73 & M & V13 & 54266 & 685 & 2.91 & 2.30 & - \\
\hline $18 / 06 / 11$ & $13: 00$ & FAD 5 & 78 & M & V13 & 54267 & 0 & 0 & 0 & - \\
\hline 18/06/11 & $13: 20$ & FAD 5 & 77 & $\mathrm{~F}$ & V13TP & 64162 & 706 & 2.85 & 2.21 & - \\
\hline $18 / 06 / 11$ & $13: 30$ & FAD 5 & 73.5 & $\mathrm{~F}$ & V13 & 54268 & 625 & 2.84 & 2.35 & - \\
\hline 20/06/11 & $13: 41$ & FAD 6 & 102 & M & V13P & 64785 & 0 & 0 & 0 & 94251 \\
\hline $20 / 06 / 11$ & $14: 00$ & FAD 6 & 69 & $\mathrm{~F}$ & V13 & 54271 & 0 & 0 & 0 & - \\
\hline $20 / 06 / 11$ & $14: 43$ & FAD 6 & 93 & M & V13TP & 64786 & 0 & 0 & 0 & 34415 \\
\hline $20 / 06 / 11$ & $15: 10$ & FAD 6 & 80.7 & $\mathrm{~F}$ & V13 & 54272 & 0 & 0 & 0 & - \\
\hline $21 / 06 / 11$ & $11: 55$ & FAD 6 & 72.3 & M & V13 & 54274 & 0 & 0 & 0 & - \\
\hline $21 / 06 / 11$ & $12: 35$ & FAD 6 & 75 & $\mathrm{~F}$ & V13TP & 64782 & 0 & 0 & 0 & - \\
\hline $22 / 06 / 11$ & $11: 45$ & FAD 7 & 77 & $\mathrm{~F}$ & V13 & 54275 & 2352 & $6.55^{\mathrm{a}}$ & 6.52 & - \\
\hline 02/04/12 & $15: 01$ & FAD 8 & 87.8 & $\mathrm{~F}$ & V13P & 7099 & 4910 & 6.38 & 6.30 & - \\
\hline 02/04/12 & $15: 11$ & FAD 8 & 79.7 & M & V13 & 54236 & 0 & 0 & 0 & - \\
\hline 03/04/12 & $07: 17$ & FAD 8 & 73.6 & M & V13 & 54284 & 0 & 0 & 0 & - \\
\hline $13 / 04 / 12$ & $15: 09$ & FAD 9 & 102 & $\mathrm{~F}$ & V13P & 7104 & 1435 & 30.60 & 26.95 & - \\
\hline $13 / 04 / 12$ & $15: 15$ & FAD 9 & 109 & $\mathrm{~F}$ & V13P & 7105 & 2364 & 30.60 & 30.15 & $990030^{\mathrm{b}}$ \\
\hline $13 / 04 / 12$ & $15: 30$ & FAD 9 & 106 & $\mathrm{~F}$ & V13 & 54280 & 7595 & 30.63 & 28.08 & 94260 \\
\hline $13 / 04 / 12$ & $15: 40$ & FAD 9 & 90 & - & V13 & 54281 & 1548 & $10.09^{\mathrm{a}}$ & 9.63 & - \\
\hline $13 / 04 / 12$ & $15: 50$ & FAD 9 & 93.3 & M & V13P & 7106 & 1495 & $10.14^{\mathrm{a}}$ & 9.74 & $990036^{\mathrm{b}}$ \\
\hline $13 / 04 / 12$ & $16: 50$ & FAD 9 & 103.3 & $\mathrm{~F}$ & V13P & 7107 & 1137 & $13.12^{\mathrm{a}}$ & 12.79 & $990028^{b}$ \\
\hline $13 / 04 / 12$ & $17: 19$ & FAD 9 & 111.8 & $\mathrm{~F}$ & V13P & 7108 & 3559 & 30.58 & 30.23 & 104678 \\
\hline $13 / 04 / 12$ & $17: 33$ & FAD 9 & 98.6 & $\mathrm{~F}$ & V13 & 54239 & 7479 & 30.55 & 30.07 & $990026^{b}$ \\
\hline $14 / 04 / 12$ & 09:35 & FAD 9 & 111.3 & - & V13 & 54240 & 7449 & 29.86 & 28.90 & 104674 \\
\hline $14 / 04 / 12$ & $11: 50$ & FAD 9 & 116 & - & V13P & 7111 & 0 & 0 & 0 & 94253 \\
\hline $14 / 04 / 12$ & $17: 39$ & FAD 9 & 116 & M & V13P & 7113 & 0 & 0 & 0 & 94255 \\
\hline $15 / 04 / 12$ & $07: 54$ & FAD 9 & 100.6 & M & V16P & $31211^{\mathrm{c}}$ & - & - & - & - \\
\hline
\end{tabular}

\section{Reception range testing}

Assuming the position of the tracking boat represented the position of the tagged fishes detected by the unidirectional hydrophone, it was possible to obtain a rough estimate of the reception range of the VR4 acoustic receiver attached to the FAD. This was achieved by comparing the detections recorded on the portable receiver (VR 100) on the tracking boat with those recorded by the VR4 on the FAD, and knowing the distance of the boat from the FAD at the time of each detection.

\section{Data analysis}

Passive monitoring analysis

Several metrics were used to describe the behavioural patterns of tagged silky sharks, which facilitated comparisons with similar work on other FADassociated species. For all analyses, an individual was defined as being present at a FAD if 2 or more detections were recorded within $1 \mathrm{~h}$. Total residence times spanned from the time of tagging until the last detection. Continuous residence times (CRTs) and continu- 
ous absence times (CATs) were calculated following Ohta \& Kakuma (2005) and Robert et al. (2013), respectively, where continuous residency was considered when no gap in detections exceeded a period of $24 \mathrm{~h}$. The first CRT was considered to begin only after any effects of capture and tagging on normal behaviour were believed to have ended (see 'Post-tagging excursions'). Fine-scale behaviour was assessed in a similar manner, using $1 \mathrm{~h}$ as the minimum period to determine presence and absence, giving rise to finescale CRTs (FCRTs) (Govinden et al. 2013) and excursions (the time between FCRTs, when the shark was beyond the of range of the receiver).

\section{Temporal behavioural patterns}

Periodicity in temporal patterns of fine-scale behaviour was assessed through spectral analysis using a fast Fourier transformation (FFT) algorithm in R (R Development Core Team 2011). This analysis detects rhythms in the time series, the periodicity of which is visible in a power spectrum (Chatfield 2004). The FFT was conducted using time series data of hourly detection frequencies generated from the start of the first CRT until the last recorded detection. The analysis was only conducted on individuals for which there were at least $3 \mathrm{~d}$ of data. The timing of excursions was assessed relative to the time of sunrise and sunset. As the FADs were constantly drifting, and tagging was conducted at different times of the year and in different areas of the ocean, using the timing of astronomical constants provided a more biologically significant reference point than simply comparing the start time of each excursion between individuals. As such, circular statistics were used to investigate whether the time differences between sunset and the start of an excursion were distributed uniformly through the night and day, or whether the data displayed directionality. For this purpose, a Rayleigh test, with a significance level of 0.05 , was performed. The distribution of arrival times (when a shark returned after an excursion) was assessed in the same manner. The time of local sunset was calculated using the position of the FAD and the calculation procedure available online from the US National Oceanic and Atmospheric Administration (NOAA) (Cornwall et al. 2014).

The duration of excursions was also compared across all individuals. As all excursions were shorter than $24 \mathrm{~h}$, it was possible to use circular statistical methods again to assess their distribution, and thus a Rayleigh test was again performed to test for uniformity in their distribution.

\section{Vertical behaviour}

Vertical behaviour was characterised using multiple comparisons corresponding to both temporal and horizontal changes in the tagged sharks' behaviour. Firstly, the behaviour between day and night was compared. This comparison facilitated the identification of possible diel changes in swimming depths or vertical movement patterns. Comparisons were performed using median swimming depths, during day and night. These comparisons were carried out using a Mann-Whitney $U$-test, as the data were found not to follow normal distributions (Shapiro-Wilks test). Day and night data were separated using the time of sunrise and sunset on the day in question, based on geographic location. Only data from individuals equipped with PSAT or archival tags were used and were restricted to their period of association with the FAD at which they were tagged. Archival tag data were preferred over depth data from acoustic tags, as they provided vertical data when the shark was both within and outside of the reception range of the acoustic receiver.

Additionally, vertical behaviour was compared over periods when the sharks were present at the FAD as well as during excursions away from the FAD. This assessment was also conducted for the same 6 individuals that had been double tagged with either PSAT or archival tags. As such, the depth data from these tags were separated into time series representing depth during a FCRT or depth during an excursion. The start and end points of these time series sections were determined by the times of the first and last detections of the acoustic tag implanted in the same animal.

To investigate the frequency with which changes in vertical behaviour occurred, spectral analysis using a FFT was conducted. As this analysis requires uninterrupted time series data, it was only performed on PSATs and archival tags that were physically recovered, thus providing the entire archived data set of the vertical behaviour sampled at 5 and $30 \mathrm{~s}$, respectively.

\section{Active tracking analysis}

The movement behaviour of the single shark that was actively tracked was assessed relative to the movement of its associated FAD by recording the distance between it and the FAD as well as it's bearing from the FAD, relative to the FAD's bearing, every minute. Girard et al. (2004) established a method for 
determining the distance from which a tracked fish displays directed orientation towards a FAD. This method involves the calculation of the reverse path length (starting from the time the fish returns to a FAD) and comparing it with the straight-line distance (backwards beeline) between the fish and the FAD throughout the course of the track (similarly calculated in reverse). These authors suggest that a linear relationship between these 2 variables is indicative of the late oriented stage of an animal seeking out a specific goal. Conversely, non-linear relationships indicate random searching. The distance at which the relationship shifts from a linear to a non-linear function indicates the orientation distance. Here, the reverse path length and backwards beeline distance were calculated for the tracked shark using the location of the shark and the location of the FAD at 1 min intervals.

\section{Interactions with other species}

The study of the behaviour of silky sharks at FADs formed part of a larger project looking at the behaviour of tunas as well as bycatch species associated with floating objects in the Indian Ocean. As such, several other species of fish were also tagged with acoustic tags at the same FADs and during the same time period as the silky sharks reported on here. These species included yellowfin tuna, bigeye tuna, skipjack tuna, rainbow runners and oceanic triggerfish. While the detailed behaviour of these species is beyond the scope of the current study, the presence of tagged individuals of these species allowed for improved interpretation of the results obtained during the active tracking experiment. During the tracking process, several of these other tagged species were also recorded. The distribution of distances from the FAD were compared between species using a Kruskal-Wallis rank sum test in the $\mathrm{R}$ software package (R Development Core Team 2011) to assess whether species-specific behaviours could be identified.

\section{RESULTS}

\section{Sharks tagged}

Of the 38 acoustically tagged sharks, 20 were detected by receivers attached to 9 different FADs (Table 2). Of the 18 sharks that were never detected, 6 were tagged at FAD 6 (Table 2) where the acoustic receiver malfunctioned, resulting in no data. The remaining 12 sharks are believed to have perma- nently left the FAD where they were tagged soon after release. While the possibility that they died cannot be excluded, data received from the PSATs fitted to 8 of these individuals indicated that they survived the tagging process. In total, data were analysed from 20 sharks tagged with coded acoustic tags, of which 5 also had a PSAT and 1 was recaptured with an internal archival tag, which was recovered after $141 \mathrm{~d}$ at liberty.

Total residence times ranged from 2.8 to $30.6 \mathrm{~d}$, with an average of $15.0( \pm 10.9 \mathrm{SD}) \mathrm{d}$. In total, the behaviour of silky sharks at drifting FADs was observed for $300 \mathrm{~d}$. Of the 20 sharks detected, observational data on 12 individuals were truncated due to either equipment failure or a fishing vessel setting a net around the FAD, resulting in the removal of the acoustic receiver and hence termination of detection data. Observations on the remaining 8 sharks were uninterrupted and final departures from the FADs at which they were tagged occurred naturally.

\section{Post-tagging excursions}

Directly after release, $90 \%(n=18)$ of the tagged sharks rapidly left the reception range of the acoustic receiver and stayed away from the FADs for $>7 \mathrm{~h}$. The mean duration of these excursions was 23.3 ( $\pm 24.0 \mathrm{SD}) \mathrm{h}$ and ranged from 0.7 to $87.7 \mathrm{~h}(3.7 \mathrm{~d})$. The majority of individuals $(75 \%)$ returned to the FAD at night. Data from double-tagged sharks showed that, once released, the tagged shark immediately descended to depths of 60 to $100 \mathrm{~m}$ before slowly returning to the upper $40 \mathrm{~m}$ after 15 to $20 \mathrm{~min}$.

\section{Continuous residence times}

Once the tagged sharks returned to the FAD, the effects of the capture and tagging operation were assumed to have ended, and 'normal' behaviour resumed. After returning, none of the tagged sharks left the detection range of a receiver for a period exceeding $24 \mathrm{~h}$ over their respective monitoring periods. The mean CRT was $14.03( \pm 10.6 \mathrm{SD}) \mathrm{d}$ and ranged between 2.21 and $30.23 \mathrm{~d}$.

\section{Periodicity and excursions}

All sharks regularly undertook short excursions away from the FAD during their respective monitoring periods (Fig. 2). The typical behaviour consisted 


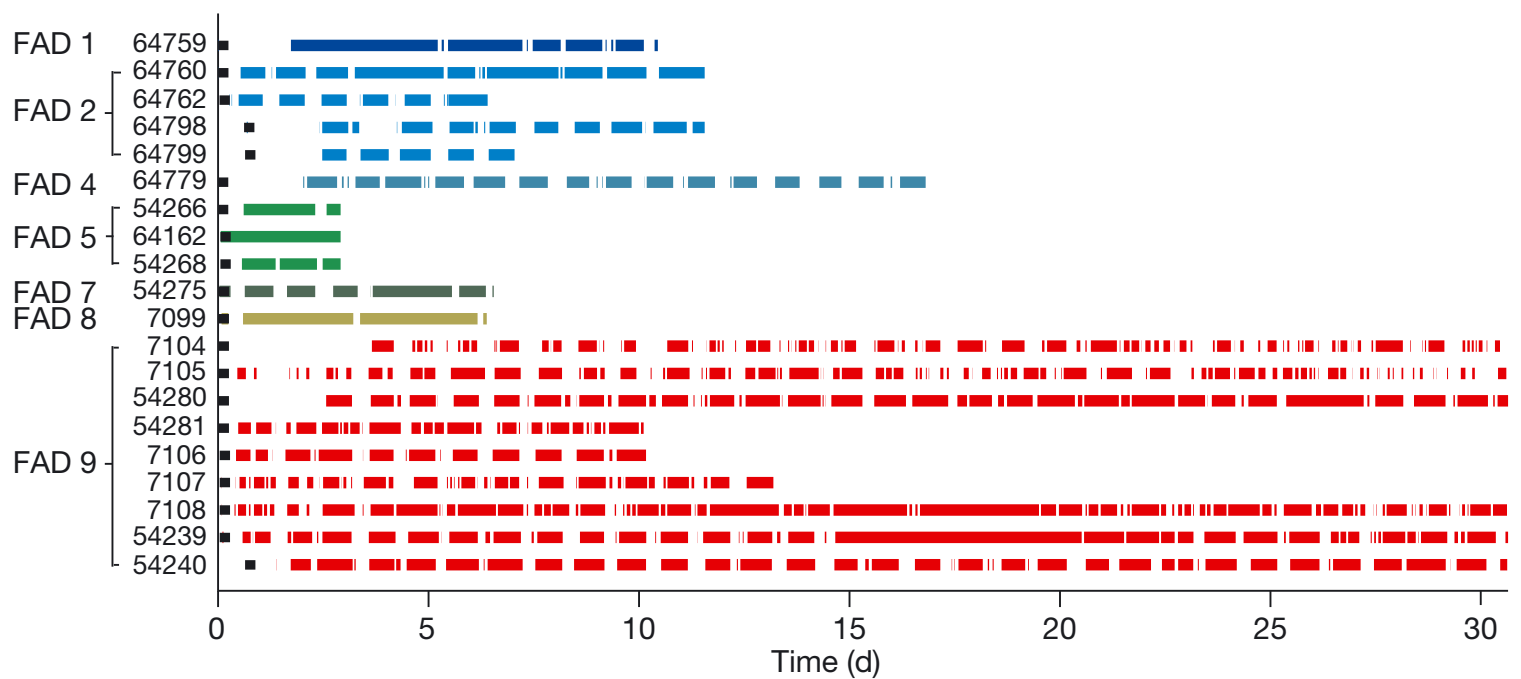

Fig. 2. Residency of tagged silky sharks Carcharhinus falciformis $(\mathrm{n}=20)$ at drifting FADs in the western Indian Ocean. Tag ID is given on the $y$-axis and duration of observation on the $x$-axis. Each horizontal series shows the presence/absence of a shark at the FAD where it was tagged (colours indicate different FADs). Coloured areas depict presence while blank spaces indicate absence. Time at which each individual was tagged relative to the tagging time of the first individual at each FAD ( $\square$ )

of presence at the FAD during the day and periods of absence during the night. The duration of these presence periods (FCRTs) averaged $7.5( \pm 10.4 \mathrm{SD}) \mathrm{h}$ while excursions were generally shorter, averaging 3.7 ( $\pm 3.0 \mathrm{SD}) \mathrm{h}$. Spectral analysis using a FFT was performed on 17 individuals that were present for $>3 \mathrm{~d}$. A distinct peak at $24 \mathrm{~h}$ in $82.4 \%$ of the individuals analysed indicated a strong diel rhythm in associative behaviour (see Fig. 3).

\section{Timing of excursions}

Circular statistics revealed that the start time of excursions was significantly clustered and not uniformly distributed over time (Rayleigh test, $\mathrm{z}=50.875$, $\mathrm{p}<0.001)$. The majority of excursions $(74 \%)$ were initiated at night, while far fewer $(26 \%)$ started between sunrise and sunset. The median start time was $95 \mathrm{~min}$ after sunset. A strong peak (22.9\% of observations) in the start of excursions was observed in the first hour after sunset (Fig. 4A). Differences between sunset and the ends of excursions showed less clustering (Fig. 4B), but were still significantly different from a uniform distribution (Rayleigh test, $\mathrm{z}=77.545, \mathrm{p}<$ 0.001). The majority of excursions ended during the night, with a median return time of $9 \mathrm{~h} 23$ min after sunset. Within the first hour after sunset, the number of excursions initiated over $10 \mathrm{~min}$ intervals increased steadily until peaking 40 to $50 \mathrm{~min}$ after sunset. A comparison with in situ light data collected from an archival tag (9900026) revealed that this
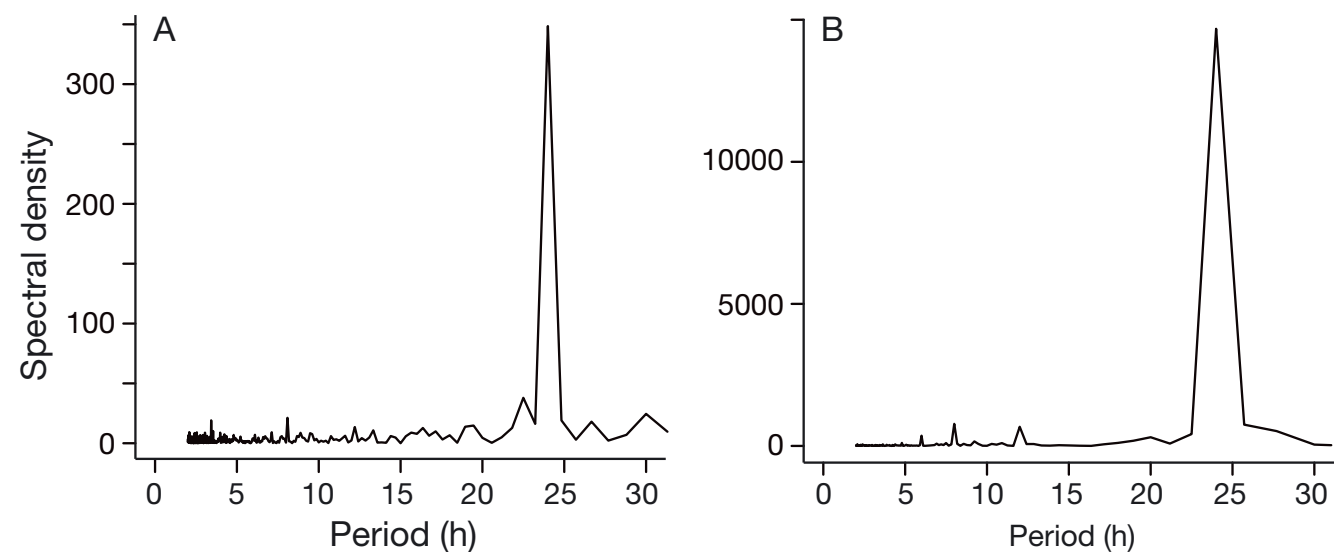

Fig. 3. Examples of fast Fourier transforms showing the diel periodicity in the presence of 2 individuals at FADs in the western Indian Ocean. (A) Tag ID 64760; (B) tag ID 64779 
A

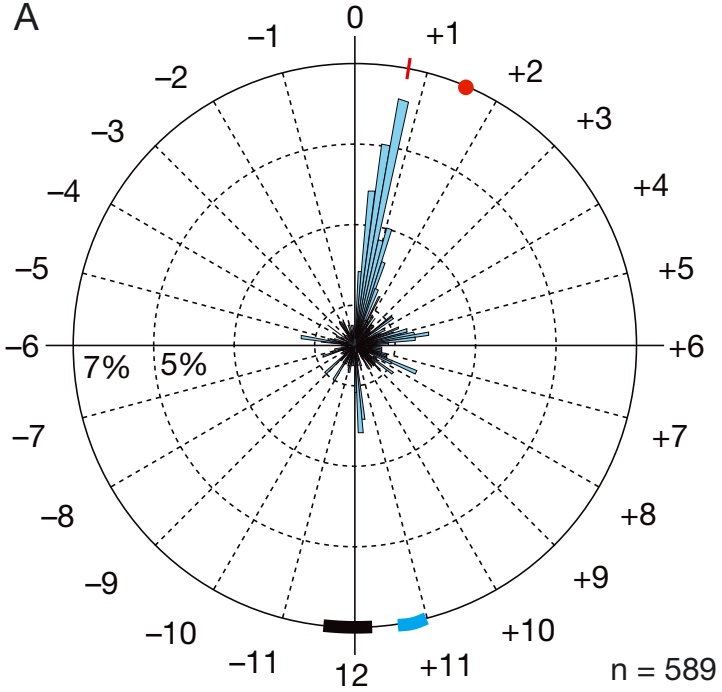

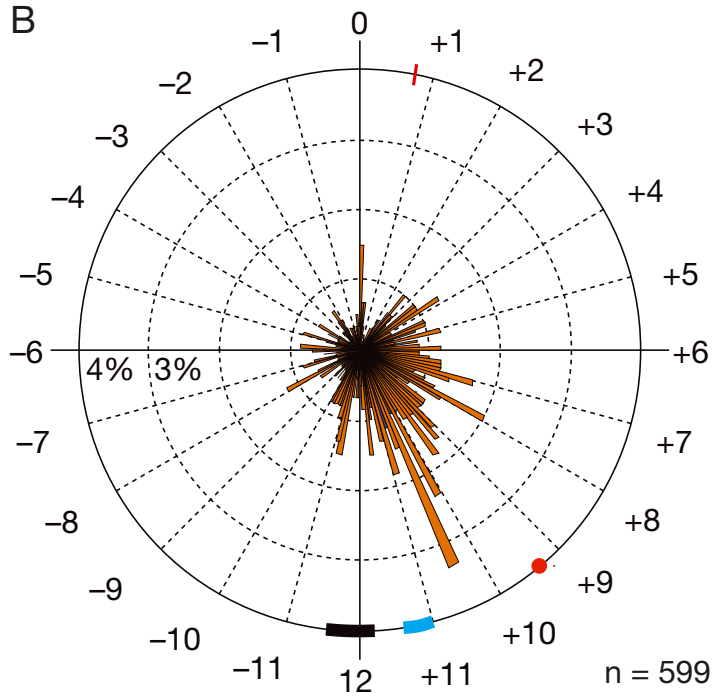

Fig. 4. Distribution of the time difference between (A) the start and (B) the end of all excursions and the time of local sunset (0) for silky sharks Carcharhinus falciformis associated with drifting FADs in the western Indian Ocean. Median values (•); red bars: nautical dusk; thick blue bars: range of times of nautical dawn; thick black bars: range of sunrise times during the study; $\mathrm{n}$ : number of departures from and returns to a FAD following absences $>1 \mathrm{~h}$

peak coincided with the time of complete darkness, as ambient light levels plateaued at a minimum (Fig. 5). This moment also corresponded exactly with time of nautical dusk. The frequency of departures decreased rapidly after this time, with minor increases occurring again roughly half way through the night and just prior to sunrise. The duration of excursions varied widely, ranging from 1 to $21.4 \mathrm{~h}$, but was strongly skewed towards short excursions lasting a few hours. The mean excursion duration was $3.7( \pm 2.98 \mathrm{SD}) \mathrm{h}$.

\section{Vertical behaviour}

Diel changes in vertical behaviour were clearly visible in the time series data collected from the PSATs and archival tags. Generally, sharks exhibited highly variable vertical behaviour during the night, moving rapidly up and down through the water column. Between these vertical excursions, the sharks were typically located close to the surface $(<10 \mathrm{~m})$. During the day, vertical movements were more restricted. For several individuals, a distinctive U-shaped pattern could be observed during the day. This shape was created by the shark remaining close to the surface at sunrise and then gradually moving deeper as midday approached, followed by a return movement to the surface as night approached (Fig. 6). FFTs on the uninterrupted time series data confirmed the periodicity of this shift in behaviour to be $24 \mathrm{~h}$. While the $24 \mathrm{~h}$ peaks in the spectrograms were clear, broad bases of

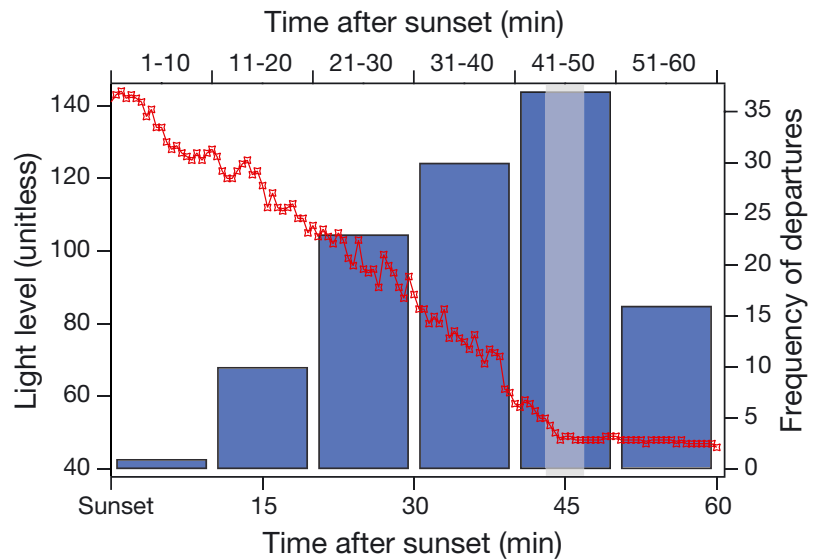

Fig. 5. An example of decreasing ambient light in the hour following sunset (red line) recorded by an archival tag (990026) in a silky shark Carcharhinus falciformis associated with FAD 9. Blue bars: frequency of silky shark departures from all monitored FADs during the first hour after sunset; grey bar: time of nautical dusk, which occurred between 44 and 48 min after sunset over the entire study period

these peaks suggested that, although the sharks regularly changed their vertical behaviour, the exact time at which the change occured differed from day to day.

A series of Shapiro-Wilks tests for normality on day and night depths showed that none of the samples were normally distributed. As such, depth distributions were compared using a non-parametric MannWhitney $U$-test. Significant differences in the median depth during day and night were found for all of the sharks, with median depths being consistently shallower at night than during the day (Fig. 7, Table 3). 


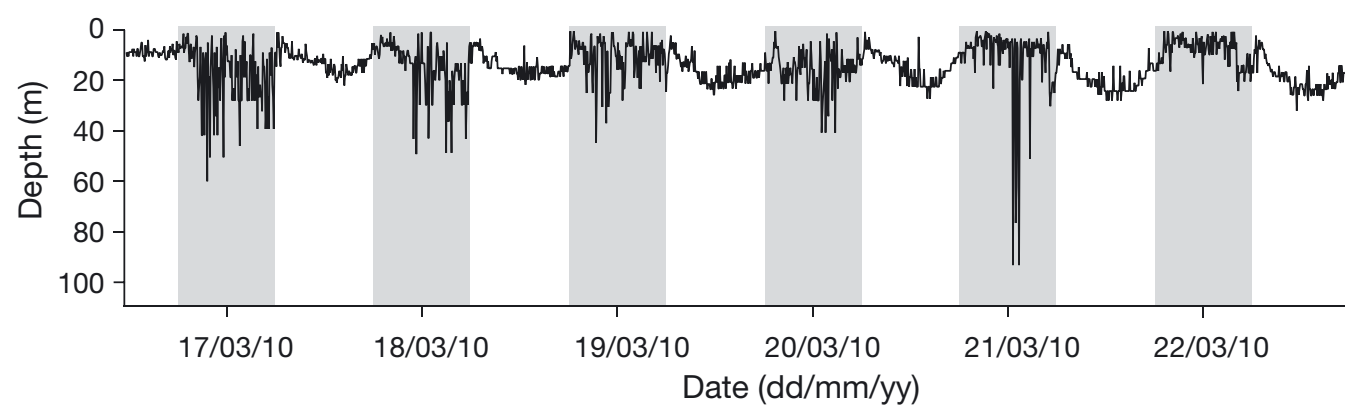

Fig. 6. Example of diel behaviour changes in vertical time series data obtained from a PSAT (34419) on a silky shark Carcharhinus falciformis at FAD 1. Grey bars indicate night. Distinctive U-shaped pattern is clearly visible during the day

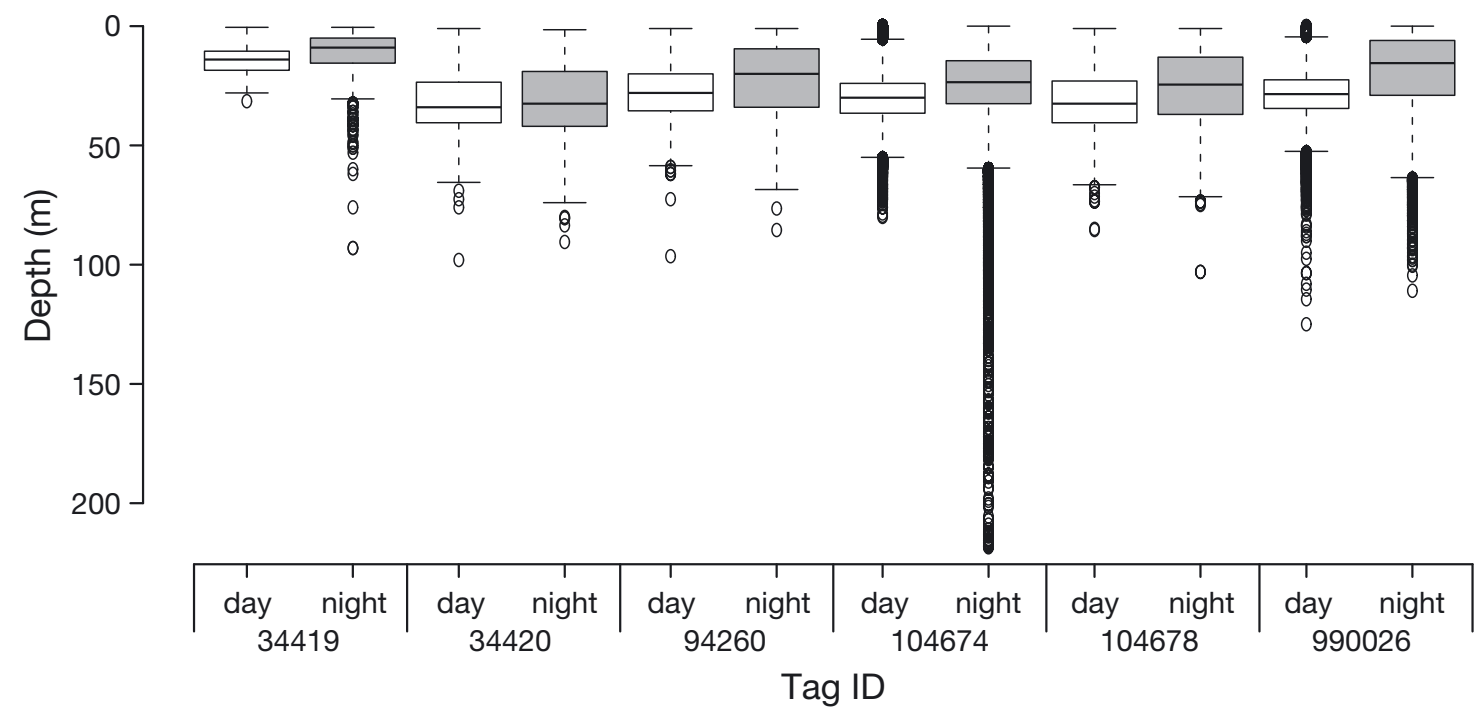

Fig. 7. Depth distributions during day and night obtained from PSAT and archival tags deployed on silky sharks Carcharhinus falciformis at drifting FADs in the western Indian Ocean. Lines within the boxes represent median values. Upper and lower ends of the boxes represent the 1st and 3rd quartiles, respectively; upper and lower whiskers indicate minimum and maximum values, respectively. (०) Outliers; white and grey shading: day and night distributions, respectively

Furthermore, the interquartile range (IQR) was always greater during the night, confirming a wider depth range at night (Fig. 7, Table 3). For comparison with other studies, day and night data were pooled across all individuals, resulting in a median depth of $27 \mathrm{~m}$ and an IQR of 19 to $35 \mathrm{~m}$.

Table 3. Summary statistics of vertical data from PSAT and archival tags deployed on silky sharks Carcharhinus falciformis associated to drifting FADs in the western Indian Ocean

\begin{tabular}{|c|c|c|c|c|c|}
\hline \multirow{2}{*}{ Tag ID } & \multicolumn{2}{|c|}{ Median depth (m) } & \multicolumn{2}{|c|}{ IQR } & \multirow{2}{*}{$\mathrm{p}$-value } \\
\hline & Day & Night & Day & Night & \\
\hline 34419 & 14 & 9 & 8 & 11 & $<2.2 \times 10^{-16}$ \\
\hline 34420 & 34 & 33 & 17 & 24 & 0.047 \\
\hline 94260 & 28 & 20 & 16 & 25 & $<2.2 \times 10^{-16}$ \\
\hline 104678 & 33 & 25 & 18 & 24 & $<2.2 \times 10^{-16}$ \\
\hline 104674 & 30 & 24 & 13 & 18 & $<2.2 \times 10^{-16}$ \\
\hline 990026 & 29 & 16 & 12 & 23 & $<2.2 \times 10^{-16}$ \\
\hline
\end{tabular}

Average depth distributions (Fig. 8A) revealed night time records were skewed towards shallower depths $(<20 \mathrm{~m})$, while day time depths were evenly distributed around a peak at approximately $30 \mathrm{~m}$. Very similar patterns were observed in the depth distributions when the sharks were present at the FAD or on an excursion (Fig. 8B). On average, the sharks were shallower during excursions, with depths of less than $15 \mathrm{~m}$ recorded most frequently. The depths occupied during periods of presence followed more of a normal bell-shaped distribution, with a peak at 30 to $39 \mathrm{~m}$.

\section{Active tracking}

Continuous manual tracking of a single shark (tag ID 31211) lasted $2 \mathrm{~h} 46 \mathrm{~min}$ and was initiated at 07:59 $\mathrm{h}$ local time. Environmental conditions were excel- 


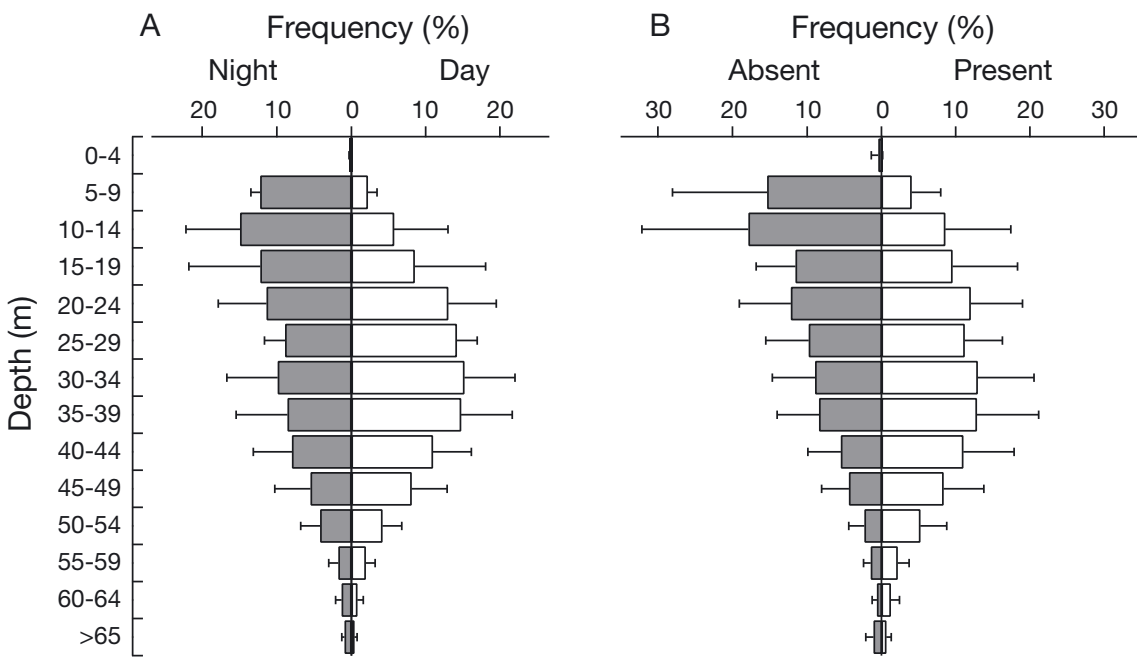

Fig. 8. Averaged depth distribution from 6 silky sharks Carcharhinus falciformis tagged with PSATs and archival tags at drifting FADs in the western Indian Ocean. (A) Comparison between night and day; (B) comparison between presence and absence at the FAD. Error bars represent standard deviations

lent during the tracking period, with less than 5 knots of wind throughout the experiment. During this time, the shark covered a total distance of $5788 \mathrm{~m}$, while the FAD drifted $2395 \mathrm{~m}$. The average speed of the shark was $0.79 \mathrm{~m} \mathrm{~s}^{-1}\left(2.50 \mathrm{~km} \mathrm{~h}^{-1}\right)$ or $0.75 \mathrm{BL} \mathrm{s}^{-1}$ (body lengths per second). Following release at the FAD, the shark moved around the FAD in a variety of directions for approximately 20 min (Fig. 9A). It then moved ahead of the FAD's direction of drift (downcurrent). The shark continued to move farther away from the FAD, maintaining a fairly constant bearing relative to the bearing of the FAD's drift. After approximately $80 \mathrm{~min}$, the drift of the FAD changed from SE to SW. Shortly after this change occurred, the shark changed direction and started swimming back towards the FAD until it reached it, and remained in close proximity for a further $20 \mathrm{~min}$, following which the experiment was terminated.

Using the reverse path length method described by Girard et al. (2004), it was possible to identify this point as the exact moment when the shark began

Table 4. Summary of spatial data collected from other tagged fishes around the drifting FAD during the active tracking of a silky shark Carcharhinus falciformis

\begin{tabular}{|lcccc|}
\hline Species & $\begin{array}{c}\text { Elagatis } \\
\text { bipinnulata }\end{array}$ & $\begin{array}{c}\text { Canthidermis } \\
\text { maculata }\end{array}$ & $\begin{array}{c}\text { Carcharhinus } \\
\text { falciformis }\end{array}$ & $\begin{array}{c}\text { Thunnus } \\
\text { albacares }\end{array}$ \\
\hline No. tagged & 3 & 4 & 11 & 5 \\
No. detected during track & 3 & 3 & 8 & 2 \\
Median distance $(\mathrm{m} \pm \mathrm{SD})$ & $76 \pm 53$ & $77 \pm 179$ & $302 \pm 326$ & $777 \pm 273$ \\
\hline
\end{tabular}

a direct orientated movement towards the FAD (Fig. 9B). This analysis indicates that the shark was able to detect the location of the FAD from $1200 \mathrm{~m}$ away and correct its trajectory constantly to compensate for the constantly changing position of the FAD, such that it would intercept it while covering the shortest possible distance.

\section{Interactions with other species}

During the course of the tracking experiment, several other tagged species were detected by the uni-directional hydrophone. As the receiver's gain was set to zero, the position of these tagged individuals was assumed to be close to that of the shark being tracked. A summary of the detection results from these fishes is provided in Table 4 . The frequency distribution of the distances at which the different species were detected showed that a clear spatial structure existed in the FAD-associated community during the time of the tracking experiment (Fig. 9C). Rainbow runners and oceanic triggerfish were detected most frequently within $100 \mathrm{~m}$ of the FAD. Other silky sharks were detected most often within $100 \mathrm{~m}$ of the FAD, but also with regular consistency throughout the trajectory of the tracked shark. Yellowfin tuna were detected most frequently at 600 to $900 \mathrm{~m}$ from the FAD, but also at the farthest point reached from the FAD during the track, at $1209 \mathrm{~m}$ (Fig. 9C). Significant differences were found between the distances at which each species was detected (Kruskal-Wallis rank sum test, df $=3$, p < 0.01). Rainbow runners and oceanic triggerfish had similar median distances, while silky sharks were detected farther away, but at an intermediate distance as compared to yellowfin tuna (Table 4).

A 3-dimensional examination of the depth and trajectory of the tracked shark and other detected fishes revealed how the shark moved relative to these individuals. A video showing this plot is available as a Supplement at www.int-res.com/ articles/suppl/m539p207_supp/. Directly after release, the shark 

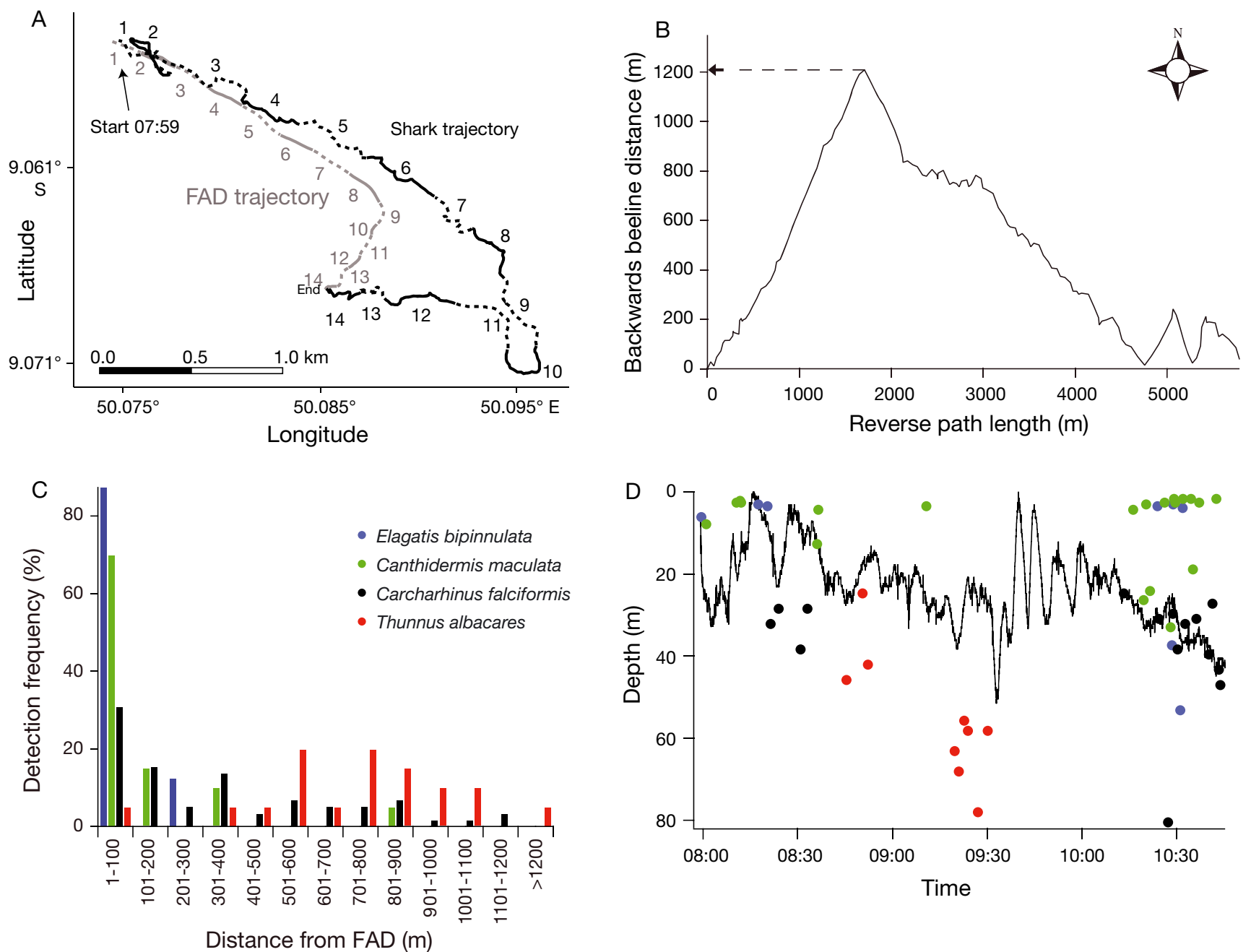

Fig. 9. (A) Horizontal movements of a silky shark Carcharhinus falciformis associated with a drifting FAD in the Indian Ocean observed during a $2.3 \mathrm{~h}$ active tracking experiment. Black line indicates the shark's movements while the grey line shows the drift of the FAD. Solid and stippled portions indicate 10 min periods while numbers show correspondence between 10 min periods. For clarity, the 20 min period after the shark returned to the FAD is not shown. (B) Assessment of the distance from which the tracked silky shark orientated to the drifting FAD using the reverse path length and beeline distance method. (C) Frequency distribution of the distances of the various species from the FAD from detections recorded from fishes equipped with both pressure-sensitive and sensor-less coded acoustic tags during the tracking experiment. (D) Depth time series data from the tracked shark as well as detections (coloured dots) of other fishes tagged with pressure-sensitive coded acoustic tags

rapidly descended to a depth of about $40 \mathrm{~m}$ (Fig. 9D). After approximately $20 \mathrm{~min}$, it made its way back to the surface where several other tagged oceanic triggerfish and rainbow runners were aggregated close to the FAD. As the shark moved away from the FAD, it was often in close proximity to other tagged sharks, and detections from those with pressure-sensitive tags showed that it descended to similar depths to some of these individuals. As the shark moved farther away from the FAD, it made its way towards a school of tuna, where several tagged yellowfin tuna were located. After approximately $1.5 \mathrm{~h}$ of tracking, the shark reached its farthest point from the FAD and descended to roughly $60 \mathrm{~m}$, where the tagged yellowfin tuna were situated (Fig. 9D). It remained at this depth only briefly, before returning to the surface. At this time, the school of tuna were observed feeding at the surface around the tracking vessel. At this point, the FAD's drift changed by $90^{\circ}$. After remaining close to the school of tuna for about $30 \mathrm{~min}$, the tracked shark started to move back towards the FAD. It encountered very few tagged fish during this portion of the track, and appeared to be focused on reaching the FAD. Once it arrived at the FAD, several other silky sharks, oceanic triggerfish and rainbow runners were again detected (Fig. 9D). The shark then remained close to the FAD for a further $20 \mathrm{~min}$, after which time the tracking experiment was terminated. 


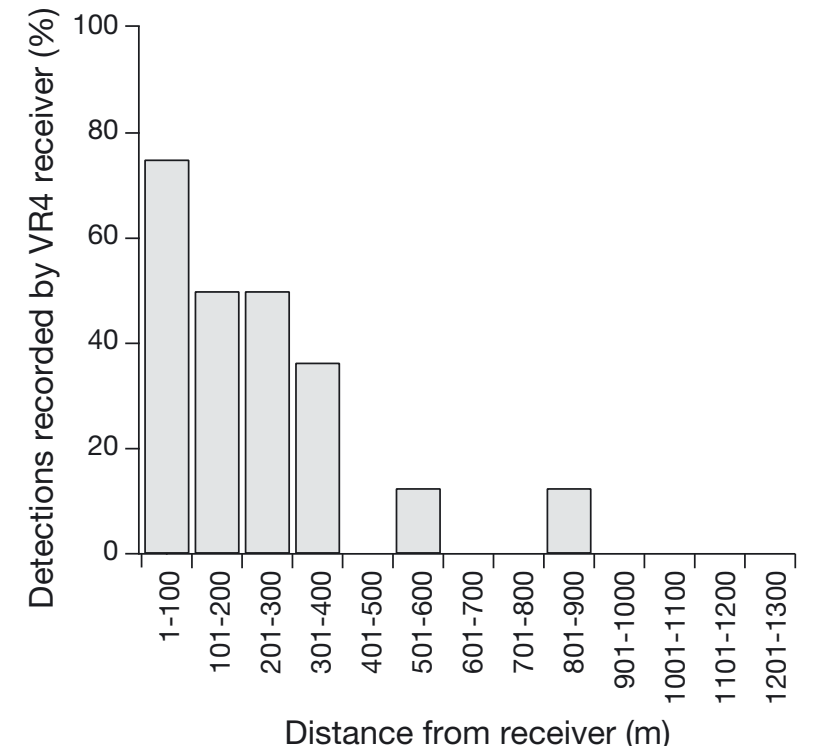

Fig. 10. Percentage of detections recorded by the VR4 receiver on the FAD in relation to the number recorded by the VR100 on the tracking vessel

\section{Reception range assessment}

A total of 106 detections were recorded from fishes tagged with coded tags by the tracking vessel during the experiment, of which $42 \%$ were also recorded by the VR4 receiver on the FAD. The maximum distance at which a detection was simultaneously recoded by both receivers was $803 \mathrm{~m}$. Beyond $400 \mathrm{~m}$ from the FAD, the percentage of simultaneous detections dropped significantly (Fig. 10). The maximum reception range obtained here was similar to those reported by other studies (655 to $680 \mathrm{~m}$ ) using acoustic receivers attached to FADs (Ohta \& Kakuma 2005, Taquet et al. 2007a).

\section{DISCUSSION}

\section{Effect of capture and tagging}

The capture and tagging of silky sharks at FADs appears to impact their normal behaviour, as a high proportion of individuals $(90 \%)$ left the monitored FAD shortly after they were released. Furthermore, $38 \%$ of tagged individuals never returned after these initial departures. Considering that after returning, not a single shark remained out of the detection range for more than $24 \mathrm{~h}$, it would appear that the stress associated with capture, handling and tagging has a significant effect on juvenile silky sharks. The duration of the 'stressed' state averaged $23.3( \pm 24.0)$ $\mathrm{h}$, after which it was assumed that the returned shark resumed 'normal' activity. Generally, studies using surgical tag implantation methods on pelagic fishes such as tunas (typically active tracking or archival tagging studies) considered the effects of tagging on behaviour to be non-significant (Holland et al. 1990, Musyl et al. 2003, Dagorn et al. 2007b, Matsumoto et al. 2013, 2014) or did not examine them directly (Schaefer \& Fuller 2002). In active tracking studies in particular, the possibility of disregarding the initial portion (hours) of an individual's behaviour is not a practical option, as such tracks typically only span several hours or days (Holland et al. 1990, Brill et al. 1999, Dagorn et al. 2000, Matsumoto et al. 2014). Furthermore, where passive acoustic techniques, such as those employed here, were used, few reported behavioural changes linked to tagging (Taquet et al. 2007a, Filmalter et al. 2011). Taquet et al. (2007a) considered dorado that left the monitored FAD within an hour of tagging to have been stressed or injured during the capture and tagging procedure, and removed these animals from their study. However, this occurred in only $13 \%$ of the studied animals. Filmalter et al. (2011), in a previous study on silky shark behaviour at FADs, also observed that all individuals left the reception range of the receiver immediately after tagging, with a mean excursion duration of $0.94 \mathrm{~d}$, which is similar to the average duration found in this study. That study also postulated the cause of this response to be the stress of capture and tagging. Interestingly, the probability of an individual returning to the FAD was lower when a PSAT was also attached to it (0.45), than when tags were only implanted internally (0.75). This result suggests that the additional stress associated with attaching an external tag is often sufficient to break the shark's association with the FAD where it was caught.

\section{Residency patterns}

After tagged sharks returned to the FAD, all individuals showed high levels of residency, until they finally left, or when the experiment was prematurely terminated. The mean total residence time of $15 \mathrm{~d}$ is almost 3 times longer than that of $5.19 \mathrm{~d}$ reported in a previous study on silky shark behaviour at FADs (Filmalter et al. 2011). As both studies were influenced by premature termination of several experiments, they likely reflect an underestimation of the typical association time of silky sharks with floating 
Table 5. Comparison of reported residence times of various species of fish associated with FADs

\begin{tabular}{|c|c|c|c|c|}
\hline Species & $\begin{array}{c}\text { Mean residence } \\
\text { time }(\mathrm{d})\end{array}$ & FAD type & Region/area & Study \\
\hline Yellowfin tuna & $\begin{array}{c}1.04 \\
7.9 \\
3 \text { to } 4 \\
0.66 \\
8.0\end{array}$ & $\begin{array}{c}\text { Drifting } \\
\text { Anchored } \\
\text { Anchored } \\
\text { Anchored } \\
\text { Anchored }\end{array}$ & $\begin{array}{l}\text { Indian Ocean } \\
\text { Japan } \\
\text { Philippines } \\
\text { Maldives } \\
\text { Hawaii }\end{array}$ & $\begin{array}{l}\text { Dagorn et al. (2007b) } \\
\text { Ohta \& Kakuma (2005) } \\
\text { Mitsunaga et al. (2012) } \\
\text { Govinden et al. (2013) } \\
\text { Dagorn et al. (2007a) }\end{array}$ \\
\hline Bigeye tuna & $\begin{array}{c}1.43 \\
7.0 \\
4.8 \\
0 \text { to } 8.6\end{array}$ & $\begin{array}{c}\text { Drifting } \\
\text { Anchored } \\
\text { Anchored } \\
\text { Drifting/anchored }\end{array}$ & $\begin{array}{c}\text { Indian Ocean } \\
\text { Japan } \\
\text { Hawaii } \\
\text { Eastern Pacific Ocean }\end{array}$ & $\begin{array}{l}\text { Dagorn et al. (2007b) } \\
\text { Ohta \& Kakuma (2005) } \\
\text { Dagorn et al. (2007a) } \\
\text { Schaefer \& Fuller (2010) }\end{array}$ \\
\hline Skipjack tuna & $\begin{array}{c}0.91 \\
2.3 \\
0.2 \\
3.5\end{array}$ & $\begin{array}{l}\text { Drifting } \\
\text { Drifting } \\
\text { Anchored } \\
\text { Anchored }\end{array}$ & $\begin{array}{c}\text { Indian Ocean } \\
\text { Central Pacific Ocean } \\
\text { Maldives } \\
\text { Maldives }\end{array}$ & $\begin{array}{l}\text { Dagorn et al. (2007b) } \\
\text { Matsumoto et al. (2014) } \\
\text { Govinden et al. (2013) } \\
\text { Govinden et al. (2013) }\end{array}$ \\
\hline Wahoo & 1.57 & Drifting & Indian Ocean & Dagorn et al. (2007b) \\
\hline Oceanic triggerfish & 12.49 & Drifting & Indian Ocean & Dagorn et al. (2007b) \\
\hline Dorado & $\begin{array}{l}3.96 \\
6.25\end{array}$ & $\begin{array}{l}\text { Drifting } \\
\text { Drifting }\end{array}$ & $\begin{array}{l}\text { Indian Ocean } \\
\text { Indian Ocean }\end{array}$ & $\begin{array}{l}\text { Dagorn et al. (2007b) } \\
\text { Taquet et al. (2007a) }\end{array}$ \\
\hline
\end{tabular}

objects. When compared with published data from other pelagic species known to aggregate at floating objects, silky sharks are the most resident (Table 5).

While differing residence times between species do not necessarily reflect different motivations for associating with a floating object, they do provide insight into the strength of the motivation to remain associated. The prolonged residence times of silky sharks suggest that the factors that cause other highly mobile pelagic teleost species, such as tunas, to break their association do not have as strong an influence on silky sharks. Ohta \& Kakuma (2005) suggested that internal state (hunger) and local prey availability may be more important in determining when tunas leave FADs than external abiotic parameters. An obvious difference between tunas and silky sharks is their energetic requirements and associated feeding strategy. FAD-associated yellowfin and bigeye tunas are generally small $(40$ to $65 \mathrm{~cm}$ ) (Dagorn et al. 2013). At this life history stage, these tunas are growing at an exponential rate (Stequert et al. 1996, Stequert \& Conand 2004), and as such have an extremely high energetic requirement. Furthermore, Ménard et al. (2000) found that $85 \%$ of the stomachs of FAD-associated tunas in the Atlantic Ocean were empty as opposed to just $26 \%$ for those caught in un-associated schools. As such, the short residence times of tunas is believed to reflect their need to find food (Ohta \& Kakuma 2005). Following this hypothesis, the long residence times of silky sharks may suggest that they are able to find sufficient food in the vicinity of the FAD to support their energetic requirements, which would certainly be lower than those of tunas.

The strong diel patterns in presence and absence from the FADs were clearly visible through the $24 \mathrm{~h}$ peak in the spectral analysis. The typical pattern consisted of presence at the FAD during the day and excursions away during the night. Night time excursions have also been observed in tunas associated with FADs (Holland et al. 1990, Ohta \& Kakuma 2005, Matsumoto et al. 2014, Forget et al. 2015), while no distinct pattern in excursion time was found for FAD-associated dorado (Taquet et al. 2007a). In spite of these temporal differences between species, all studies attributed excursion away from the FAD to foraging behaviour. The high regularity of departure events and their temporal precision following sunset suggests that the onset of darkness is the major stimulus for sharks to initiate a switch in behavioural mode (association vs. excursion). This is further emphasised by the exact correlation of the strongest peak in departure frequency with the time at which ambient light levels reached a minimum. The duration of excursions was highly variable, with a mean of $3.7( \pm 2.9 \mathrm{SD})$ h. However, nearly all excursions that started after dark ended before sunrise, with excursions that started later typically being shorter than those that started soon after sunset. These findings suggest that the behav- 
iour adopted during excursions (such as capturing prey) may be more effective during hours of darkness, possibly due to improved capture efficiency or an increase in prey abundance during this time (e.g. diel vertically migrating species moving into the surface layer). Furthermore, the duration of the excursion may be related to the feeding success, with shorter excursions indicating more successful feeding bouts. Testing this hypothesis will require simultaneous tracking and feeding observations, as have been performed for short fin mako sharks Isurus oxyrinchus (Sepulveda et al. 2004). Dietary data from silky sharks associated with FADs in the eastern Pacific Ocean suggest that in that area, sharks feed predominantly on other FAD-associated species, with mesopelagic species forming only a minor component of the diet (Duffy et al. 2015); however, similar information on diel changes in associative behaviour from this region is still lacking. In a recent study, Forget et al. (2015) illustrated that the patterns of presence of silky sharks and tunas at drifting FADs in the Indian Ocean were quite similar. Both the sharks and the tunas were more closely associated with the FAD during the day and more dispersed during the night. As such, there is a possibility that the different species respond to similar environmental cues, which may include the behaviour of the other species in the aggregation. It follows that the excursions displayed by silky sharks may be influenced by the departure of schools of tunas, but close examination of the data presented by Forget et al. (2015) suggests that the departure of the tunas and sharks is asynchronous, with the sharks typically leaving a few hours after the tunas. Furthermore, several sharks in that study were tagged at FADs where tuna schools were not present, yet behavioural patterns were similar. The details of the complex interspecific interactions that likely exist in such aggregations certainly require dedicated research attention in the future.

The strong diel behaviour suggests that there may be an opportunity to capitalise on this behaviour to minimise the capture of sharks. However, the results presented by Forget et al. (2015) indicate that fishing at FADs is synchronised with the time at which tunas are the most likely to be present, at dawn. This also coincides with a high probability of silky shark presence. Essentially, any management measure that required fishers to set their nets at times when the silky sharks were unlikely to be close to the FAD would result in a major reduction in the capture of the target tunas and, as such, appears to be a poorly suited solution to the mitigation of silky shark capture.

\section{Vertical behaviour}

The FFT analysis of the complete time series of vertical data from recovered PSAT and archival tags clearly indicates a strong diel periodicity in the silky shark's vertical behaviour. A general pattern was evident across all individuals, where median depths were significantly shallower at night than during the day. However, the consistently larger IQR at night suggests that, despite a generally shallower distribution, the sharks also spent short periods of time descending to greater depths than during daylight hours. Individual comparison of day/night IQRs suggests that during the day, the sharks exhibited a more consistent vertical behaviour, seldom undertaking large vertical movements. Musyl et al. (2011) also found significant differences between day and night depths of silky sharks tagged with PSATs in the Pacific Ocean, and reported that sharks spent the majority of their time $(95 \%)$ in the surface layers (above $120 \mathrm{~m}$ ). Both the pooled median depth $(32 \mathrm{~m}$ ) and the IQR (11 to $48 \mathrm{~m}$ ) of immature silky sharks in that study were similar to those found here (median depth $=27 \mathrm{~m}, \mathrm{IQR}=19$ to $35 \mathrm{~m}$ ). The general pattern of moving deeper at night and shallower during the day has been reported for other pelagic fish species that typically remain above the thermocline. These include dorado (Merten et al. 2014) and the oceanic whitetip shark (Howey-Jordan et al. 2013). However, the opposite pattern has been found for bigeye tuna (Holland et al. 1990, Schaefer \& Fuller 2002), swordfish Xiphias gladius (Dewar et al. 2011) and pelagic shark species with wider vertical ranges, such as the short fin mako (Sepulveda et al. 2004), common thresher Alopias vulpinus (Cartamil et al. 2011), bigeye thresher Alopia supercilliosus (Weng \& Block 2004, Musyl et al. 2011) and blue shark Prionace glauca (Musyl et al. 2011). This behavioural pattern is believed to reflect the feeding strategy of these species, which involves feeding on meso-pelagic species in the deep scattering layer (DSL) at depth during the day and then tracking the diel migration of the DSL to the surface layers during the night (Holland et al. 1990, Potier et al. 2007). While the depth range utilised by the silky sharks observed here was greater at night, it is still similar to the shallow nocturnal depth range of pelagic species known to track the nocturnal migration of the DSL (Josse et al. 1998, Dagorn et al. 2000, Schaefer \& Fuller 2002). The lack of large daytime vertical oscillations, generally associated with feeding activity, further suggests that FAD-associated silky sharks feed primarily at night. 


\section{Active tracking}

The active tracking experiment described here is the first of its kind on this species in the pelagic environment. While this experiment was initially designed to provide insight into the response of silky sharks to the stress of capture and tagging, it ultimately provided an unprecedented first glance into multiple forms of behavioural information. These included the shark's ability to home towards a FAD, the horizontal and vertical structure of the FAD-associated fish assemblage, and how the shark interacted with this community.

The effect of capture and tagging on the tracked individual was consistent with other tagged silky sharks, as it left the reception range of the receiver shortly after release. However, the duration of this initial excursion was far shorter than the average obtained from other tagged sharks (slightly more than $2 \mathrm{~h}$ as opposed to the average of $24.9 \mathrm{~h}$ ). During this excursion, the shark showed a clear pattern of remaining downcurrent from the FAD. Furthermore, it appeared to make orientated movements towards a school of tuna that was located approximately $1 \mathrm{~km}$ downcurrent of the FAD. The position of the tuna school observed here is consistent with similar observations made by Schaefer \& Fuller (2005), who found that tagged skipjack and bigeye tunas were consistently located downcurrent of a drifting vessel in the eastern Pacific Ocean. Both the trajectory of the shark and the reverse path length analysis clearly indicate that the shark was able to navigate directly to the position of the FAD from more than $1 \mathrm{~km}$ away. While results from a single tracked animal over a short period of time should certainly be considered preliminary, they do provide interesting insight into how the shark might perceive its environment. The lack of detections of other fishes during the shark's return leg to the FAD, followed by abundant detections of other silky sharks, triggerfish and rainbow runners once it arrived, suggest that the close proximity of these species to the FAD may aid the sharks ability to locate it. As such, the biomass of the intranatant and extranatant community (Freon \& Dagorn 2000) may play a significant role in detectability of a FAD by silky sharks. The homing distance reported here is similar to that obtained for dorado by Girard et al. (2007) at anchored FADs, but is significantly shorter than distances reported for tunas ( 7 to $10 \mathrm{~km}$ ) (Girard et al. 2004, Moreno et al. 2007). The significant spatial structure of the FAD aggregation is consistent with the definitions of extranatant and circumnatant species described by Freon \& Dagorn
(2000) and applied by Taquet et al. (2007b) to species at FADs in the western Indian Ocean.

\section{CONCLUSIONS}

The results obtained through this telemetry study suggest that tagging and handling influenced the behaviour of silky sharks in the short term. After normal behaviour was resumed and they re-associated with the FAD, they displayed very regular spatiotemporal behavioural patterns. In general, they remained close to the FAD during the day, and undertook limited vertical movements. As darkness fell they left the immediate vicinity of the FAD, and started to undertake rapid vertical oscillations, which likely reflect feeding activity. Then, after a variable length of time but still during the hours of darkness, the sharks returned to the FAD. By the time the sun had risen, they had settled back into a more stable vertical behavioural state. Despite this strong behavioural pattern, mitigation measures requiring fishing sets to be carried out at night are unlikely to be accepted as they would result in major reductions in tuna catch (Forget et al. 2015). The long residence times observed here suggest that associating with drifting objects is an important behavioural strategy for juvenile silky sharks and further highlights their vulnerability to incidental capture in the intensive FAD-based tuna fishery (Filmalter et al. 2013, Poisson et al. 2014, Hutchinson et al. 2015).

Acknowledgements. We thank R. Govinden, G. Berke, M. Soria, J. Lopez and R. Bennett for their assistance with fieldwork. Our gratitude is also extended to the skippers and crews of the various vessels from which this work was carried out. The research was financially supported by the commission of the European communities, FP 7, 'Theme 2-Food, agriculture, fisheries and biotechnology', through the research project MADE, contract no. 210496 and the Bycatch mitigation project of the International Seafood Sustainability Foundation (ISSF). J.F. and F.F. received $\mathrm{PhD}$ grants from the ISSF during the course of the study.

\section{LITERATURE CITED}

Amandè MJ, Ariz J, Chassot E, de Molina $\mathrm{AD}$ and others (2010) Bycatch of the European purse seine tuna fishery in the Atlantic Ocean for the 2003-2007 period. Aquat Living Resour 23:353-362

Brill RW, Block BA, Boggs CH, Bigelow KA, Freund EV, Marcinek DJ (1999) Horizontal movements and depth distribution of large adult yellowfin tuna (Thunnus albacares) near the Hawaiian Islands, recorded using ultrasonic telemetry: implications for the physiological ecology of pelagic fishes. Mar Biol 133:395-408 
Cartamil DP, Sepulveda CA, Wegner NC, Aalbers SA, Baquero A, Graham JB (2011) Archival tagging of subadult and adult thresher sharks (Alopias vulpinus) off the coast of southern California. Mar Biol 158:935-944

Chatfield C (2004) The analysis of time series: an introduction. Chapman \& Hall/CRC, Boca Raton, FL

Cornwall C, Horiuchi A, Lehman C (2014) NOAA ESRL sunrise/sunset calculator. www.esrl.noaa.gov/gmd/grad/ solcalc/sunrise.html Date accessed: 21/08/2014

> Dagorn L, Bach P, Josse E (2000) Movement patterns of large bigeye tuna (Thunnus obesus) in the open ocean, determined using ultrasonic telemetry. Mar Biol 136: 361-371

Dagorn L, Holland KN, Itano DG (2007a) Behavior of yellowfin (Thunnus albacares) and bigeye ( $T$. obesus) tuna in a network of fish aggregating devices (FADs). Mar Biol 151:595-606

Dagorn L, Pincock DG, Girard C, Holland KN and others (2007b) Satellite-linked acoustic receivers to observe behavior of fish in remote areas. Aquat Living Resour 20: 307-312

> Dagorn L, Holland KN, Restrepo V, Moreno G (2013) Is it good or bad to fish with FADs? What are the real impacts of the use of drifting FADs on pelagic marine ecosystems? Fish Fish 14:391-415

> Dewar H, Prince ED, Musyl MK, Brill RW and others (2011) Movements and behaviors of swordfish in the Atlantic and Pacific oceans examined using pop-up satellite archival tags. Fish Oceanogr 20:219-241

Duffy LM, Olson RJ, Lennert-Cody CE, Galván-Magaña F, Bocanegra-Castillo N, Kuhnert P (2015) Foraging ecology of silky sharks, Carcharhinus falciformis, captured by the tuna purse-seine fishery in the eastern Pacific Ocean. Mar Biol 162:571-593

Filmalter JD, Dagorn L, Cowley PD, Taquet M (2011) First descriptions of the behavior of silky sharks, Carcharhinus falciformis, around drifting fish aggregating devices in the Indian Ocean. Bull Mar Sci 87:325-337

Filmalter JD, Capello M, Deneubourg JL, Cowley PD, Dagorn L (2013) Looking behind the curtain: quantifying massive shark mortality in fish aggregating devices. Front Ecol Environ 11:291-296

Forget F, Capello M, Filmalter JD, Govinden R, Soria M, Cowley PD, Dagorn L (2015) Behaviour and vulnerability of target and non target species at drifting FADs in the tropical tuna purse seine fishery determined by acoustic telemetry. Can J Fish Aquat Sci 72:1398-1405

> Freon P, Dagorn L (2000) Review of fish associative behaviour: toward a generalisation of the meeting point hypothesis. Rev Fish Biol Fish 10:183-207

> Gilman EL (2011) Bycatch governance and best practice mitigation technology in global tuna fisheries. Mar Policy 35:590-609

Girard C, Benhamou S, Dagorn L (2004) FAD: fish aggregating device or fish attracting device? A new analysis of yellowfin tuna movements around floating objects. Anim Behav 67:319-326

Girard C, Dagorn L, Taquet M, Aumeeruddy R, Peignon C, Benhamou S (2007) Homing abilities of dolphinfish (Coryphaena hippurus) displaced from fish aggregating devices (FADs) determined using ultrasonic telemetry. Aquat Living Resour 20:313-321

Govinden R, Jauhary R, Filmalter JD, Forget F, Soria M, Adam S, Dagorn L (2013) Movement behaviour of skipjack (Katsuwonus pelamis) and yellowfin (Thunnus alba- cares) tuna at anchored fish aggregating devices (FADs) in the Maldives, investigated by acoustic telemetry. Aquat Living Resour 26:69-77

Holland KN, Brill RW, Chang RKC (1990) Horizontal and vertical movements of yellowfin and bigeye tuna associated with fish aggregating devices. Fish Bull 88:493-507

> Howey-Jordan LA, Brooks EJ, Abercrombie DL, Jordan LKB and others (2013) Complex movements, philopatry and expanded depth range of a severely threatened pelagic shark, the oceanic whitetip (Carcharhinus longimanus) in the western North Atlantic. PLoS ONE 8:e56588

> Hutchinson MR, Itano DG, Muir JA, Holland KN (2015) Postrelease survival of juvenile silky sharks captured in a tropical tuna purse seine fishery. Mar Ecol Prog Ser 521: 143-154

Josse E, Bach P, Dagorn L (1998) Simultaneous observations of tuna movements and their prey by sonic tracking and acoustic surveys. Hydrobiologia 371-372:61-69

Lopez J, Moreno G, Sancristobal I, Murua J (2014) Evolution and current state of the technology of echo-sounder buoys used by Spanish tropical tuna purse seiners in the Atlantic, Indian and Pacific oceans. Fish Res 155:127-137

> Matsumoto T, Kitagawa T, Kimura S (2013) Vertical behavior of bigeye tuna (Thunnus obesus) in the northwestern Pacific Ocean based on archival tag data. Fish Oceanogr 22:234-246

> Matsumoto T, Satoh K, Toyonaga M (2014) Behavior of skipjack tuna (Katsuwonus pelamis) associated with a drifting FAD monitored with ultrasonic transmitters in the equatorial central Pacific Ocean. Fish Res 157:78-85

Ménard F, Stéquert B, Rubin A, Herrera M, Marchal É (2000) Food consumption of tuna in the equatorial Atlantic Ocean: FAD-associated versus unassociated schools. Aquat Living Resour 13:233-240

Merten W, Appeldoorn R, Rivera R, Hammond D (2014) Diel vertical movements of adult male dolphinfish (Coryphaena hippurus) in the western central Atlantic as determined by use of pop-up satellite archival transmitters. Mar Biol 161:1823-1834

Mitsunaga Y, Chikayuki E, Anraku K, Selorio CMJ, Babaran RP (2012) Association of early juvenile yellowfin tuna Thunnus albacares with a network of payaos in the Philippines. Fish Sci 78:15-22

Moreno G, Dagorn L, Sancho G, Itano DG (2007) Fish behaviour from fishers' knowledge: the case study of tropical tuna around drifting fish aggregating devices (DFADs). Can J Fish Aquat Sci 64:1517-1528

> Musyl MK, Brill RW, Boggs CH, Curran DS, Kazama TK, Seki MP (2003) Vertical movements of bigeye tuna (Thunnus obesus) associated with islands, buoys, and seamounts near the main Hawaiian Islands from archival tagging data. Fish Oceanogr 12:152-169

Musyl MK, Brill RW, Curran DS, Fragoso NM and others (2011) Postrelease survival, vertical and horizontal movements, and thermal habitats of five species of pelagic sharks in the central Pacific Ocean. Fish Bull 109:341-368

> Ohta I, Kakuma S (2005) Periodic behavior and residence time of yellowfin and bigeye tuna associated with fish aggregating devices around Okinawa Islands, as identified with automated listening stations. Mar Biol 146: 581-594

> Poisson F, Filmalter JD, Vernet AL, Dagorn L (2014) Mortality rate of silky sharks (Carcharhinus falciformis) caught in the tropical tuna purse seine fishery in the Indian Ocean. Can J Fish Aquat Sci 71:795-798 
Potier M, Marsac F, Cherel Y, Lucas V, Sabatie R, Maury O, Ménard F (2007) Forage fauna in the diet of three large pelagic fishes (lancetfish, swordfish and yellowfin tuna) in the western equatorial Indian Ocean. Fish Res 83: 60-72

R Development Core Team (2011) R: a language and environment for statistical computing. R Foundation for Statistical Computing, Vienna

Robert M, Dagorn L, Filmalter JD, Deneubourg JL, Itano DG, Holland KN (2013) Intra-individual behavioral variability displayed by tuna at fish aggregating devices (FADs). Mar Ecol Prog Ser 484:239-247

Schaefer KM, Fuller DW (2002) Movments, behavior, and habitat selection of bigeye tuna (Thunnus obesus) in the eastern Pacific, ascertained through archival tags. Fish Bull 100:765-788

Schaefer KM, Fuller DW (2005) Behavior of bigeye (Thunnus obesus) and skipjack (Katsuwonus pelamis) tunas within aggregations associated with floating objects in the equatorial eastern Pacific. Mar Biol 146:781-792

Schaefer KM, Fuller DW (2010) Vertical movements, behavior, and habitat of bigeye tuna (Thunnus obesus) in the equatorial eastern Pacific Ocean, ascertained from archival tag data. Mar Biol 157:2625-2642

Sempo G, Dagorn L, Robert M, Deneubourg JL (2013) Impact of increasing deployment of artificial floating

Editorial responsibility: Scott Shaffer,

San Jose, California, USA objects on the spatial distribution of social fish species. J Appl Ecol 50:1081-1092

Sepulveda CA, Kohin S, Chan C, Vetter R, Graham JB (2004) Movement patterns, depth preferences, and stomach temperatures of free-swimming juvenile mako sharks, Isurus oxyrinchus, in the Southern California Bight. Mar Biol 145:191-199

Stequert B, Conand F (2004) Age and growth of bigeye tuna (Thunnus obesus) in the western Indian Ocean. Cybium 28:269-274

Stequert B, Panfili J, Dean JM (1996) Age and growth of yellowfin tuna, Thunnus albacares, from the western Indian Ocean, based on otolith microstructure. Fish Bull 94: 124-134

Taquet M, Dagorn L, Gaertner J, Girard C (2007a) Behavior of dolphinfish (Coryphaena hippurus) around drifting FADs as observed from automated acoustic receivers. Aquat Living Resour 20:323-330

Taquet M, Sancho G, Dagorn L, Gaertner J and others (2007b) Characterizing fish communities associated with drifting fish aggregating devices (FADs) in the western Indian Ocean using underwater visual surveys. Aquat Living Resour 20:331-341

Weng KC, Block BA (2004) Diel vertical migration of the bigeye thresher shark (Alopias superciliosus), a species possessing orbital retia mirabilia. Fish Bull 102:221-229

Submitted: June 26, 2014; Accepted: October 6, 2015

Proofs received from author(s): November 3, 2015 